\title{
Living Donor Liver Transplant Using Dual Grafts
}

\author{
Vladislav Brașoveanu ${ }^{1}$, Dragoș Zamfirescu' ${ }^{2}$, Mihail Pautov ${ }^{1}$, Ion Barbu ${ }^{1}$, Irinel Popescu ${ }^{1}$
}

Corresponding author:

Mihail Pautov, MD

General Surgeon

"Dan Setlacec" General Surgery

and a Liver Transplant

Fundeni Clinical Institute

Centre of Excellence in Translational

Medicine

258, Sos. Fundeni, 022328

Bucharest, Romania

E-mail: contact@doctormihail.ro
${ }^{1}$ Fundeni Clinical Institute, Bucharest, Romania

2Zetta Plastic and Reconstructive Microsurgery Clinic, Bucharest, Romania

\section{ABSTRACT}

Living donor liver transplant predisposes both the donor and the recipient to high risk of small residual liver volume (in donor) and small-for-size graft syndrome (in recipient) (1). Both of these risks can be overcomed by using two grafts from two different donors; this procedure is called "Living donor liver transplant using dual grafts" (2). We present a video case-report of a "Living donor liver transplant using dual grafts" performed in a 51 yo female recipient for $\mathrm{VHB}+\mathrm{VHD}$ cirrhosis, MELD score 22. She received two liver grafts, a left hemiliver (Donor 2 in the video) and a left lateral section (Donor 1 in the video). The combined GRWR was $1.05(0.71+0.34)$. For a better understanding of the technique, both donation and back-table procedures were combined in the same split-screen, being followed by the left lateral section (Donor 1) and left hemiliver (donor 2) implantations. Both donors had no postoperative complications. After 12 months of follow-up, both donors and the recipient are alive, with normal liver function. Dual-graft Living donor liver transplant is a feasible option to achieve the required liver volume using two suboptimal liver grafts.

Key words: living donor liver transplant, dual graft, dual transplant, liver transplant

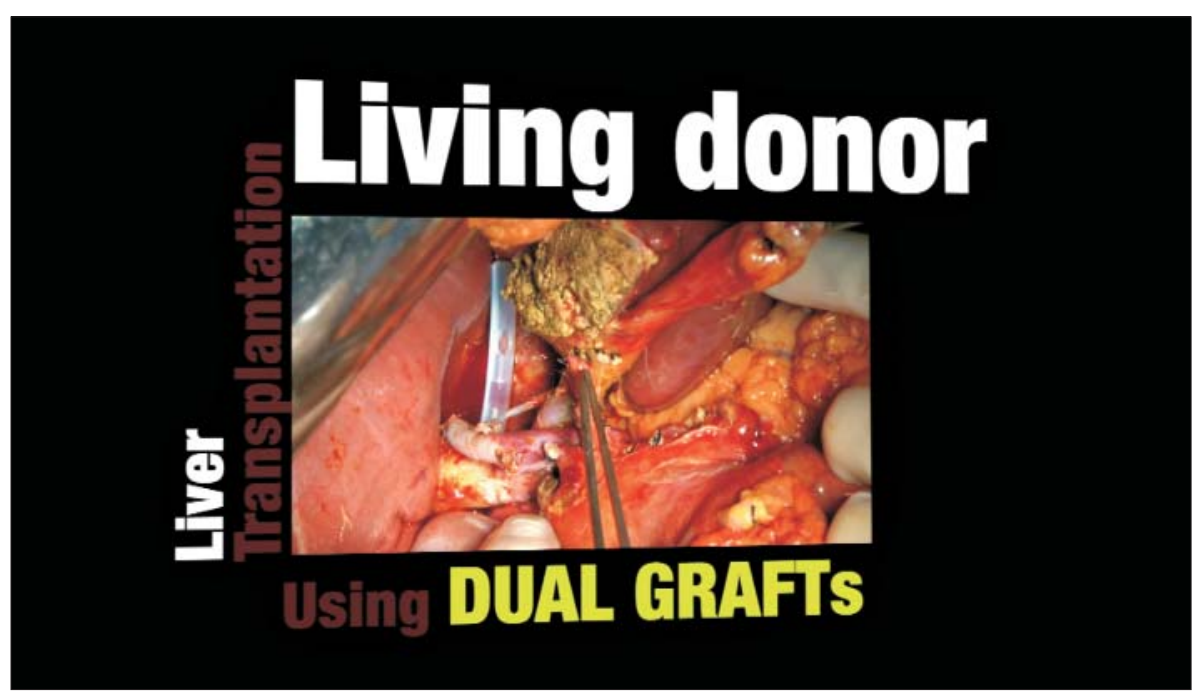



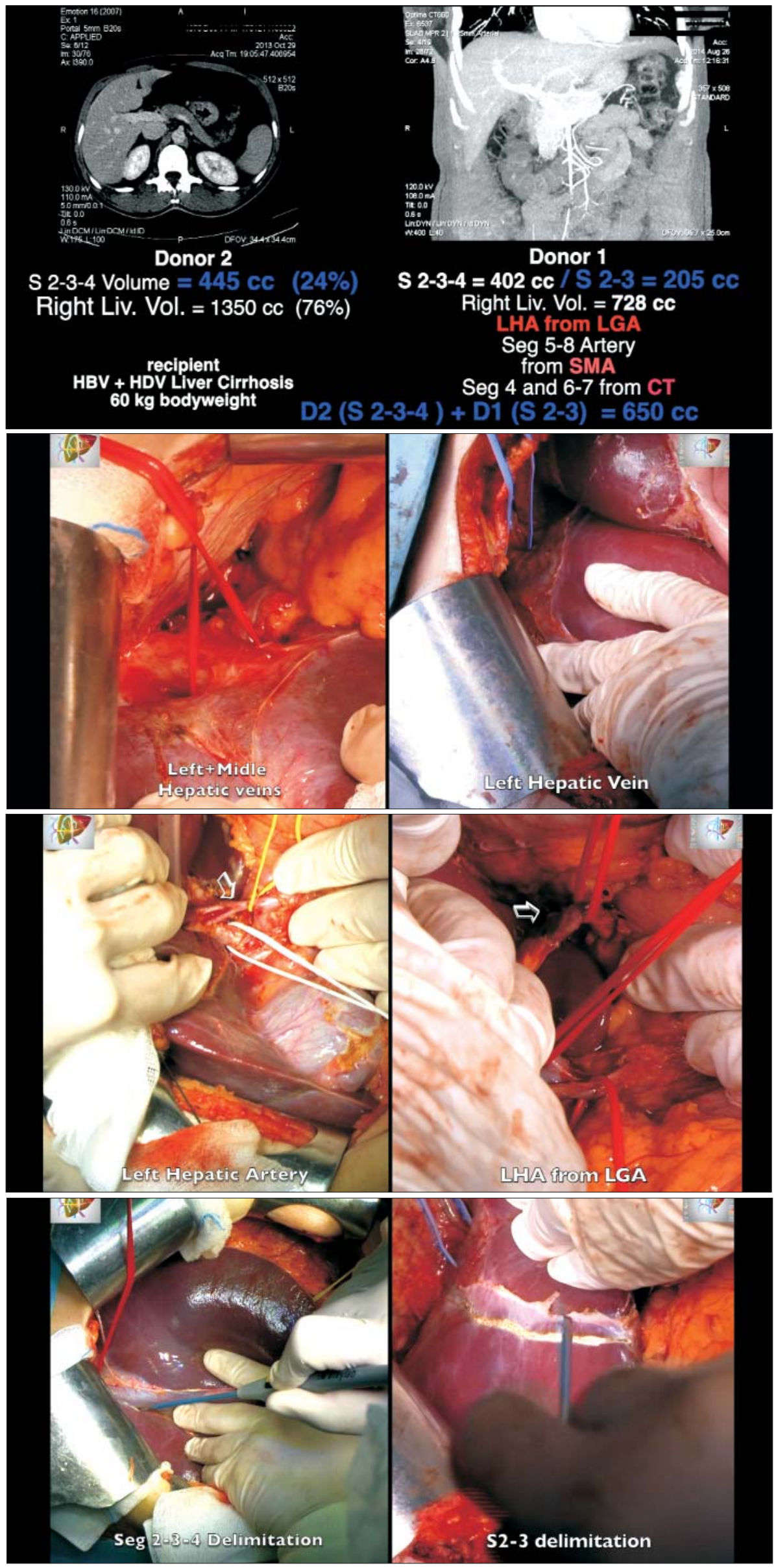

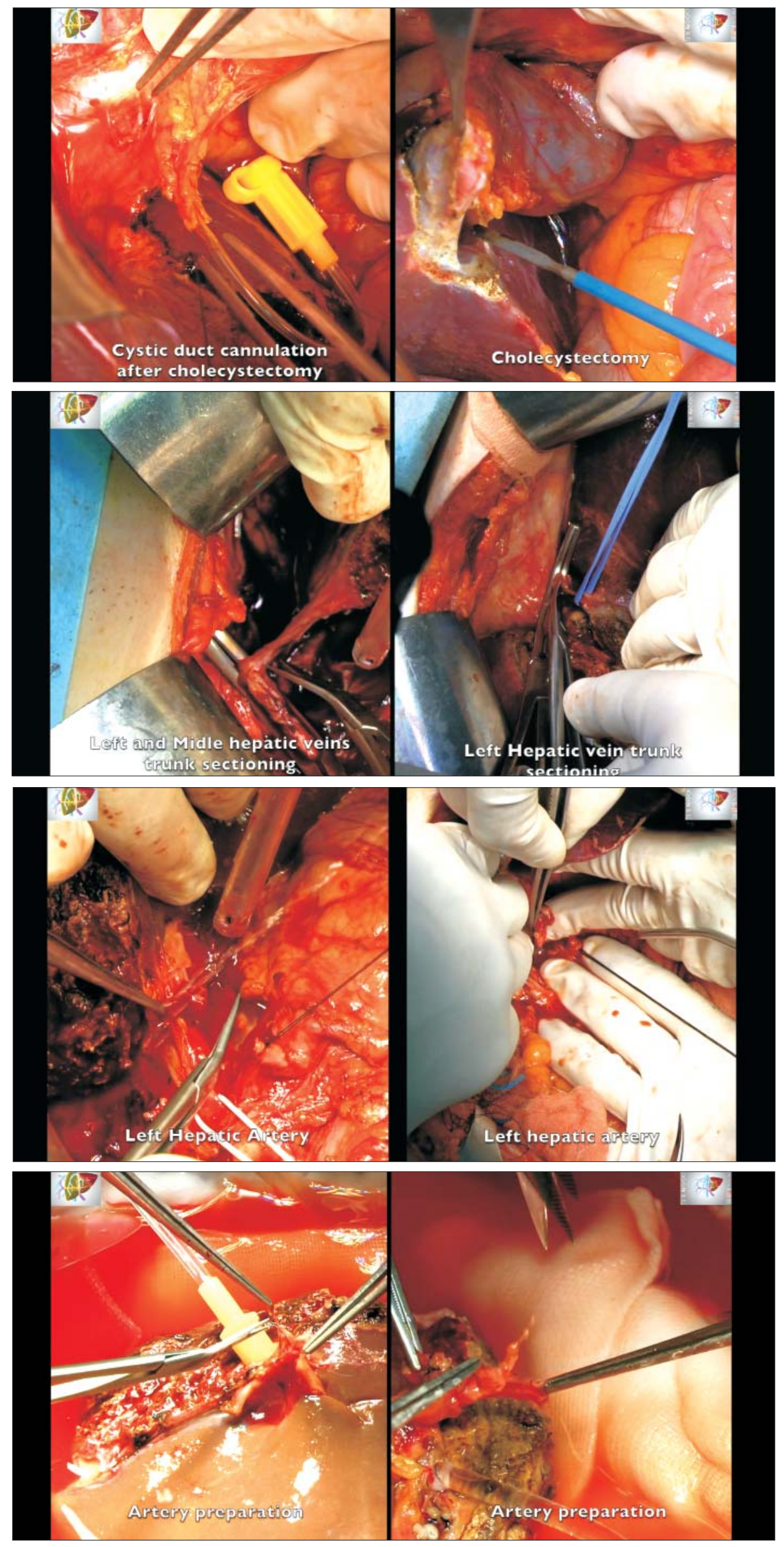

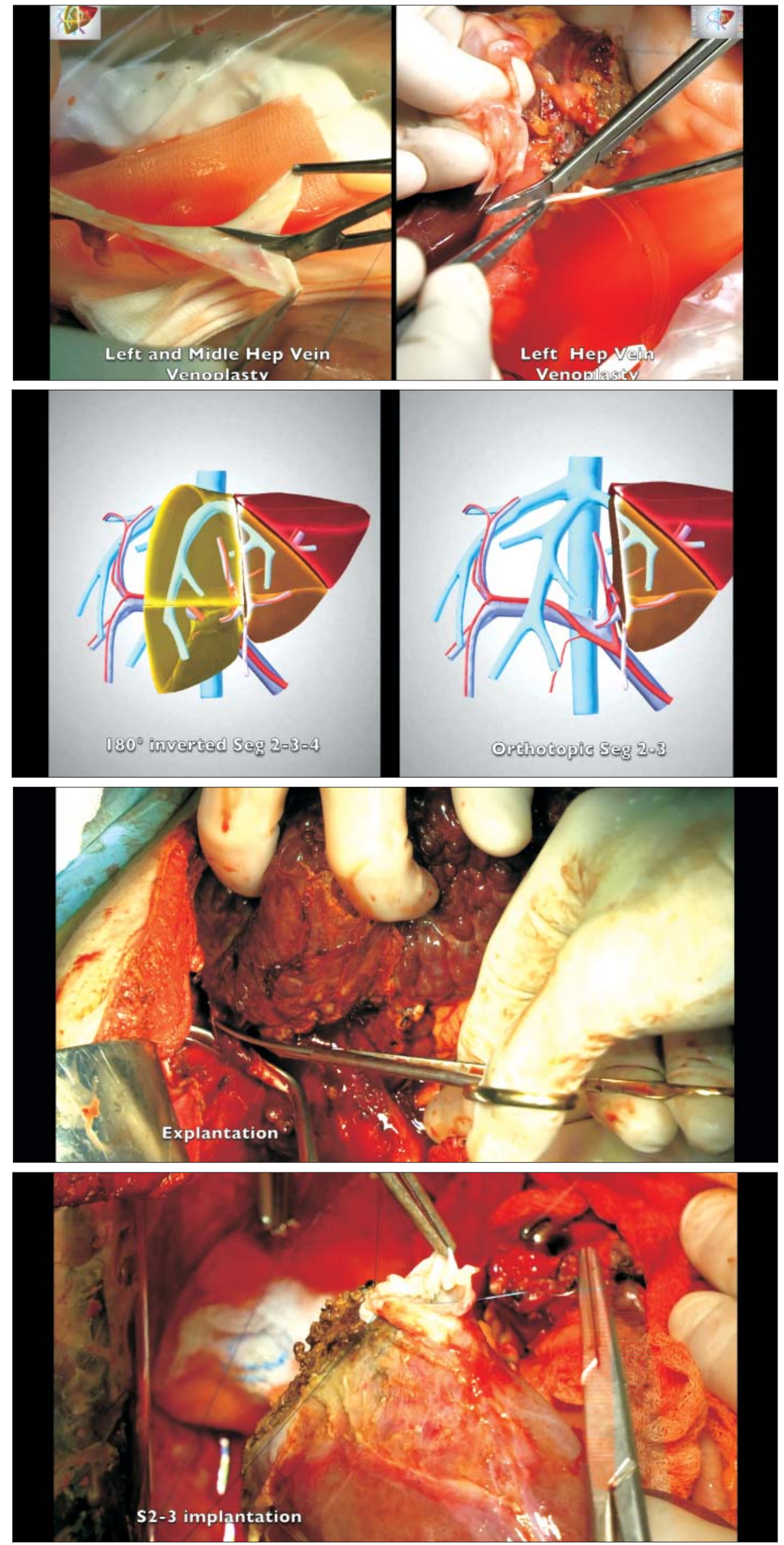

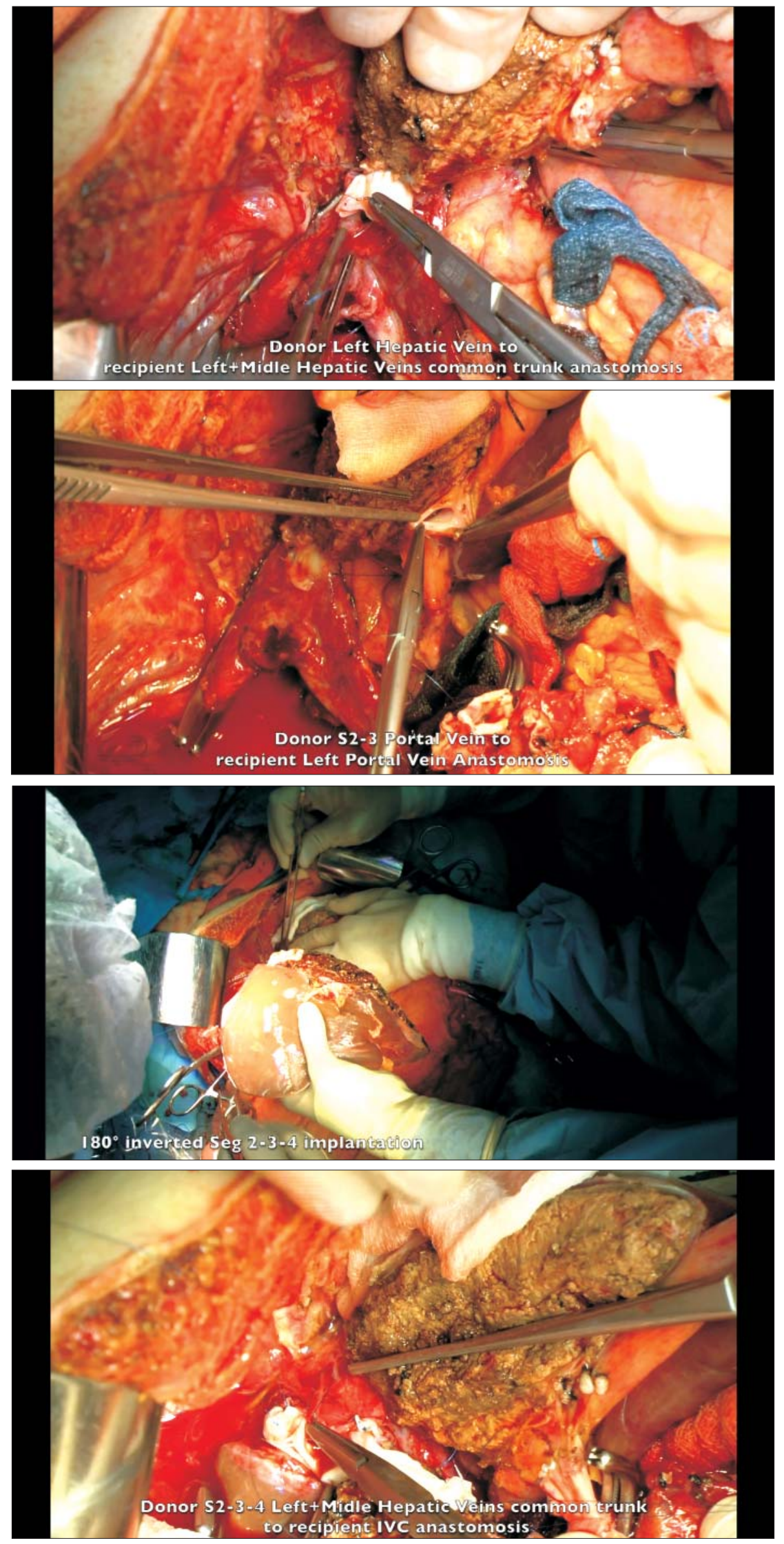

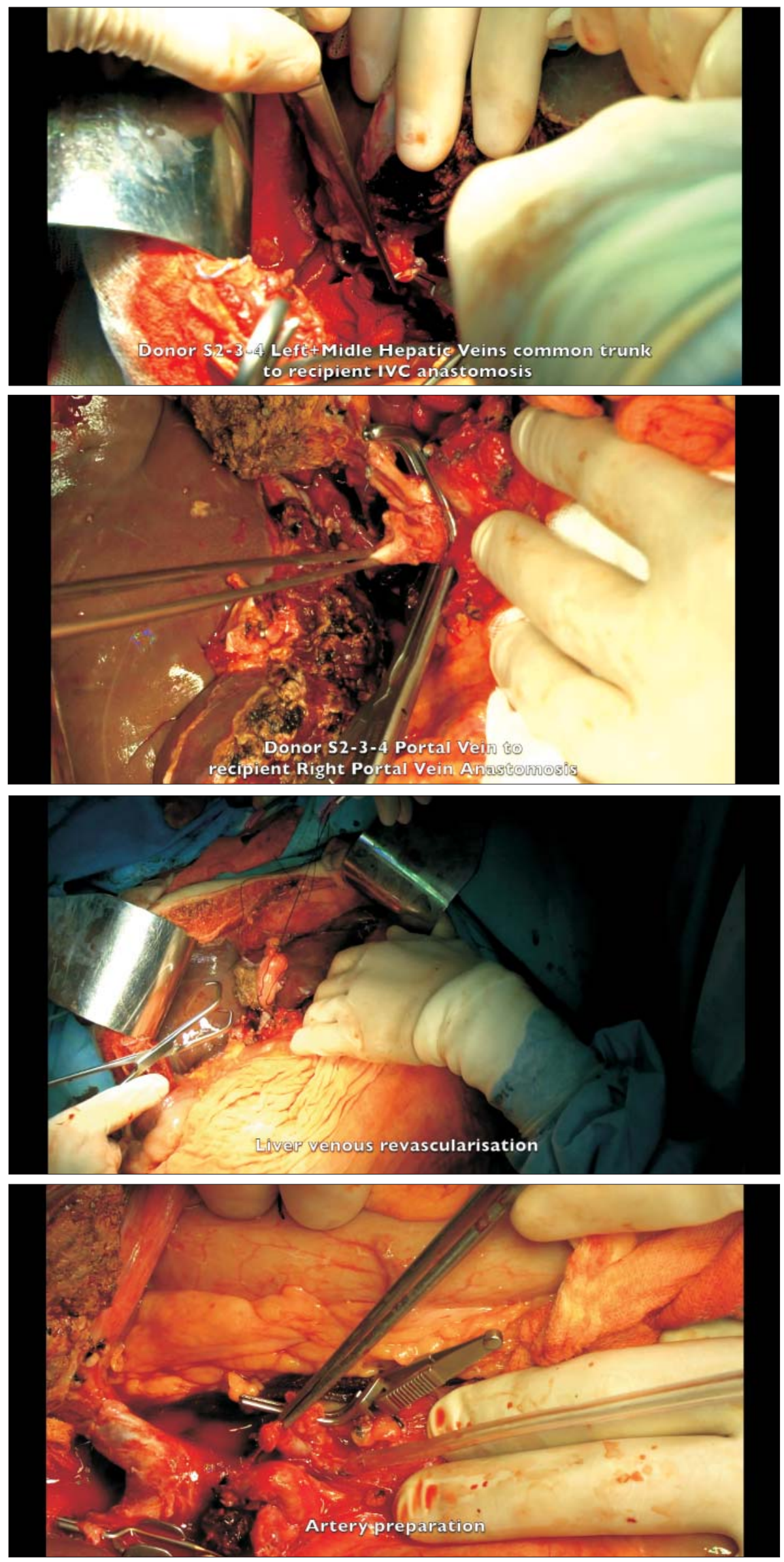

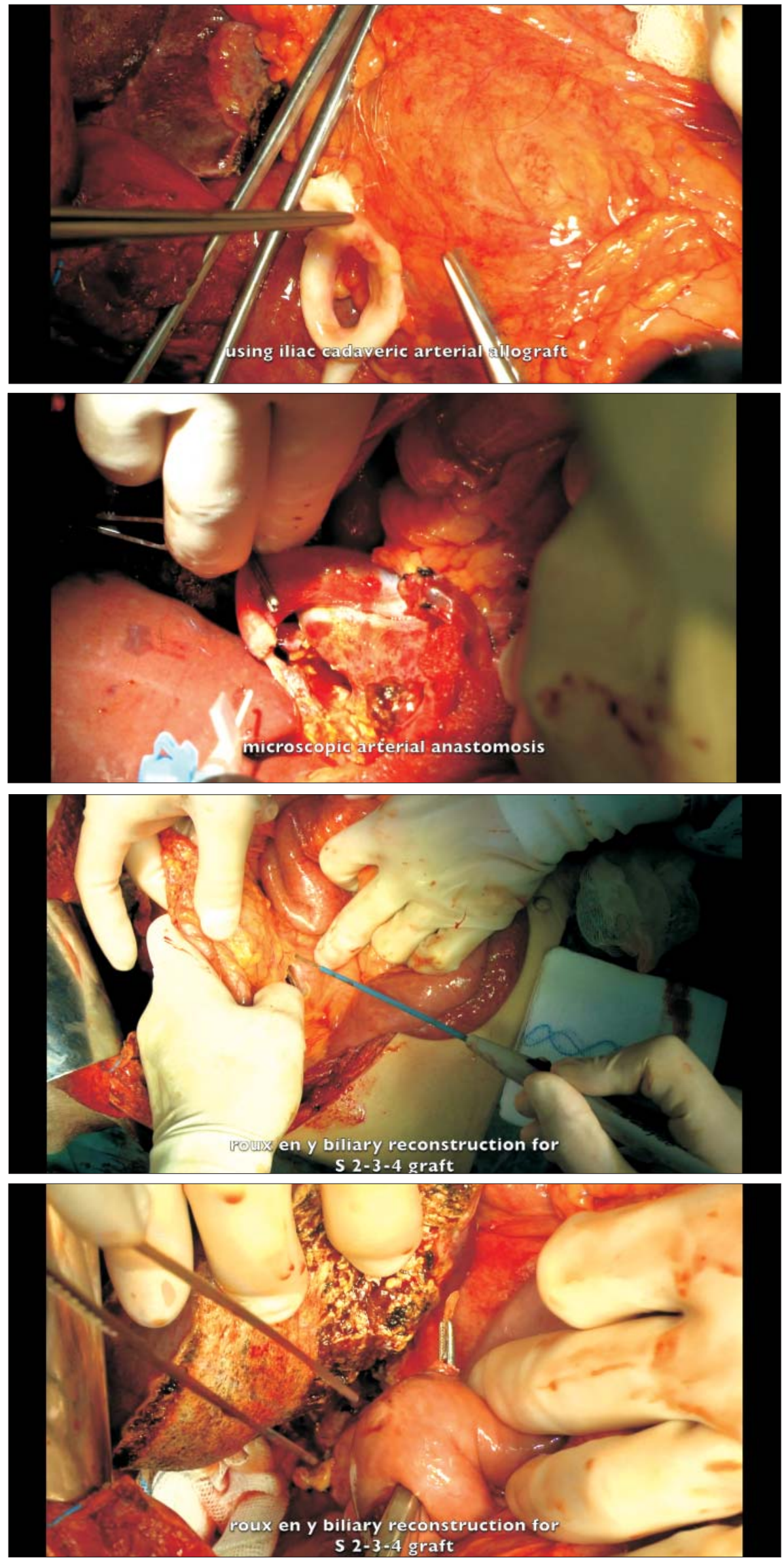

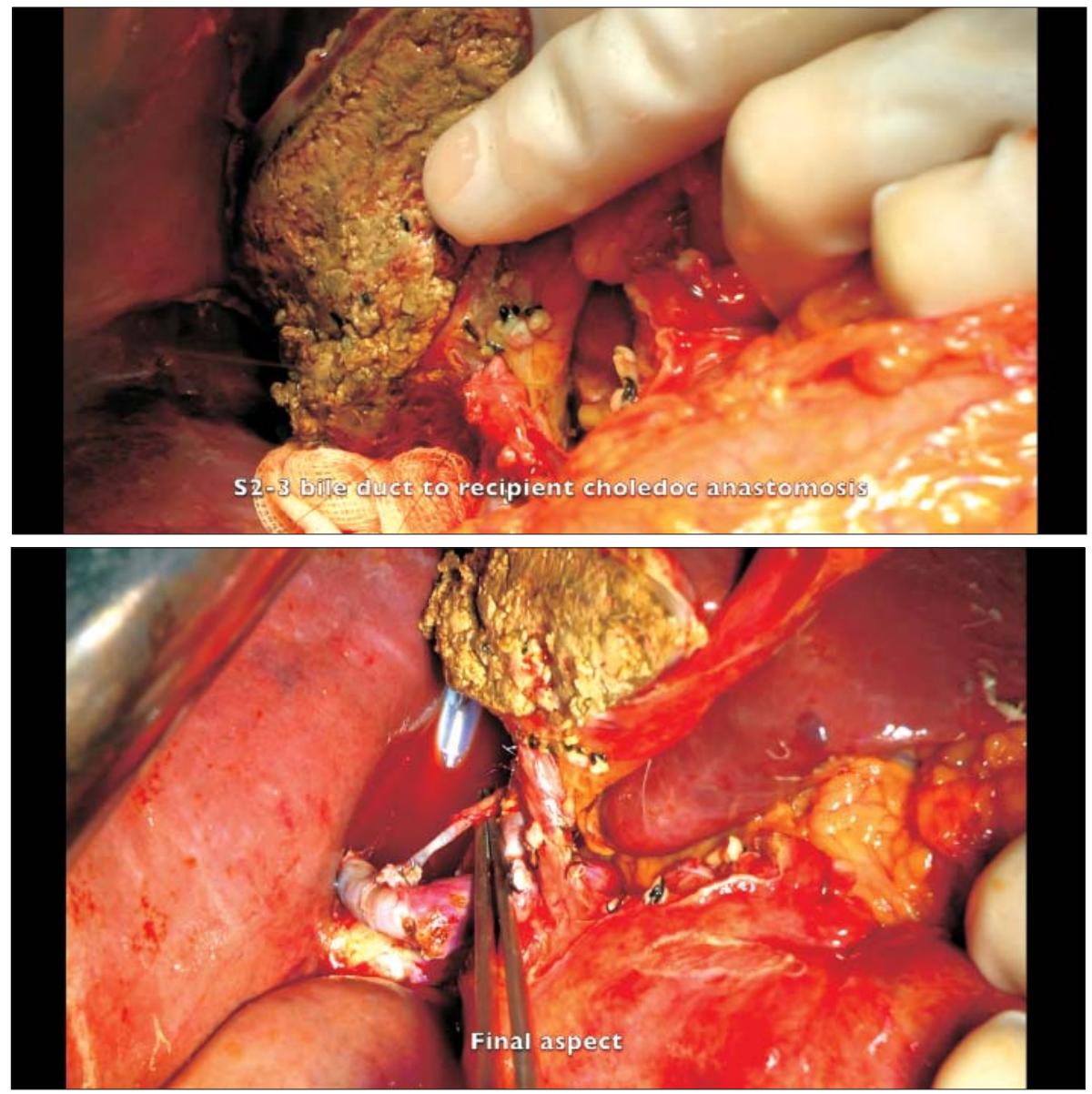

\section{Conflict of interest}

All author declare that they have no conflict of interest.

\section{REFERENCES}

1. Xu Y, Chen H, Yeh H, Wang H, Leng J, Dong J. Living donor liver transplantation using dual grafts: Experience and lessons learned from cases worldwide. Liver Transpl. 2015;21(11):1438-48.

2. Botea F, Brasoveanu V, Constantinescu A, Ionescu M, Matei E, Popescu I. Living donor liver transplantation with dual grafts -- a case report. Chirurgia (Bucur). 2013;108(4):547-52. 